\title{
Supporting Strategic Planning Decision-Making in Higher Education by Developing IDSS using Open Source Dashboard Technology
}

\author{
Alhanoof Mohammed ALhumayan \\ Faculty of Computer and Informationn Technology \\ King Abdulaziz University \\ Saudi Arabia, Jeddah
}

\author{
Abdullah Saad AL-Malaise \\ Faculty of Computer and Informationn Technology \\ King Abdulaziz University \\ Saudi Arabia, Jeddah
}

\begin{abstract}
The strategic planning model fits into the best characteristics of higher education institutions. Regarding recent developments in Saudi higher education policies, we note that from the perspective of the Government, the proposed biennial planning system for higher education seems to fit the elements of the interpretive model and calls upon institutions to plan in an interpretive manner. Open Source Dashboard Technology IT plays an inevitable role in integrating the IDSS (Intelligent Decision Support System) in Establishment of higher education in technology for revolutionary decisionmaking. Due to modern factors, decision-making requires the complexity of business knowledge and data and data representation, therefore, an intelligent computer system is required. "IDSS is an intelligent information system that reduces the time when environmental decisions are made and improves the coherence and quality of decisions [Haagsma \& Johanns, 1994]." Decision makers are trying to apply new strategies and use new tools to transform data into useful information that can contribute in solving administrative problems. Decision makers require reports that are accurate, timely, and that give the entire "work image". Dashboard Technology and Intelligent Decision Support System (IDSS). Systems come to save decision makers. This paper proposes the integration of open source information technology and IDSS to improve the quality and effectiveness of higher education systems. The control panel enables executives to measure, control and manage organizational performance more effectively. If the IDSS are be applied to higher education using Open Source Dashboard Technology processes, it will help to improve student performance, manage their lifecycle, identify potential students, design a training course, and choose courses to measure their retention rate, infrastructure, and develop and manage a foundation grant fund. This is an approach to study the impact of the use of open source information technology and IDSS for higher education institutions in strategic planning. Finally, the Higher Education Planning System (IDSS) was be introduced to illustrate and evaluate the use of dashboard techniques as intelligence tools and decision-making tools and The analysis was conducted through two basic methods: the questionnaire of the questions and the direct interviews. The results were high to reflect the level of awareness and development in the higher education environment
\end{abstract}

\section{Keywords}

Higher Education (HE), Intelligent Decision Support System (IDSS), Decision Making (DM).

\section{INTRODUCTION}

Strategic planning is essential to any organization because it assists in dealing with any unexpected or predicted issue that might arise. Firms that plan and use strategies in their operations tend to have a competitive advantage, strategic planning helps in the development of Smart goals, as well as foreseeing the possible outcomes. The quantitative and qualitative performance metrics allow firms to measure their progress easily. Intelligent Decision Support System (IDSS) will enable institutions to make more informed decisions through the use of strategic plan evolution and modification especially in student's' admission this system will help making more accurate and fast decisions. This field also allows users to interact with the dashboard technology that guides them through the decision-making process. With this system in place, users can make solid decisions on any computer and at any location. Furthermore, academic institutions will be able to manage their resources well through the uses of IDSS. Incorporating DSS in higher learning will help in decreasing costs, as well as saving time, which can then invest in other productive activities. The decision support system will enlighten the school's mission and innovative investigation. Quality evaluation is vital to DSS because it ensures that the decision-making system is be based on reliable information. This process also creates room for transparency and responsibility. Quality evaluation has disciplines and laws that need to be respect since they guide decision-making philosophies. A quality evaluation can also improve the accuracy of DSS systems. Through it, institutions can access correct details that will boost their performance. There are various methods will be used in analyzing the quality of data. First method is through use of a monitoring tool. This technique is quite popular among individuals since it allows them to have better control of the evaluation process [3]. Today, there are a lot of software's and tools that can used to carry out the evaluation process. Tasks can analyze easily through a particular criterion that has been present. This aspect tends to improve reliability and accuracy of the evaluation method. However, the measuring tool may bring false results if wrong variables are used. The second method is the analytic hierarchy process. It makes uses human judgments to boost the planning and decision-making process. The final method is goal and question metric model (GQM) can used. However, this model requires all the characteristics and metrics to define before the GQM method can be set up. According to research, GQM model is quite appropriate when it comes to generating appropriate measures. At the end of the analysis, an individual can easily tell which goals have been achieve through the model. The research proposal will deal with the problem of supporting strategic planning decisionmaking in higher education by developing IDSS using dashboard technique. The performance of the developed system will be evaluated will be evaluated by how much 
impact it makes on learning institutions. Various factors such as the speed of making a relevant, quick, and good decision in higher institutions will used to evaluate the technology. The research for this proposal will compare its results with other outcomes that were present by other surveys conducted before this. The sample number of institutions and students will be increased. There will a comparison of those institutions that embrace the technology and the ones that reject it. The research will employ the use of a statistical tool to build and measure the model. Some of the tools that will used in the project include a laptop, phone, articles, books, writing materials, and the internet. These items will ensure that the project is carry out successfully.

\section{MOTIVATIONS}

Higher education institutions use strategic planning to make better decisions and anticipate the results of any decision or process. It also allows for avoiding obstacles and problems that delay planning and lack of success such as routine and administrative complexity, and thus delay in response from individuals and entities that follow the institution. However, information on these systems is not always accurate. Therefore, the use of IDSS, the quality of the information providing the mechanism of transmission and delivery to the parties concerned will improve the decision-making rate, and will increase the levels of the different departments within the organization, thus saving a lot of time and effort. That ultimately improves the overall education process in the institution. In addition, Kothari (2004: 15) states that there are several motives for conducting a research study, including providing service to society, updating and improving existing systems, gaining respectability and solving some slow-making processes of decisions. Based on my close contact with the people working in the educational institutions in the public sector, I feel motivated because this may help to address some of the directives of government in important issues such as employment conditions, looking for innovative solutions to long-standing problems and to be socially and technically interactive and proactive.

\section{HYPOTHESIS AND RESEARCH METHODS}

\subsection{The Research Objectives}

The researcher aims to investigate how IDSS in higher education can developed using open source dashboard technology. Therefore, the researcher hypothesizes "the IDSS using open source dashboard technology provides efficiency, flexibility and problem-solving in the strategic planning processes in higher education". The following three objectives of the research:

1. To Study the Intelligent Decision Support System (IDSS) and state their limitations.

2. To develop IDSS using open source dashboard technique

3. To analyze the obtained results and compare them with the expected reference.

\subsection{The research questions}

The current research study investigates the main research question: how efficient is the efficiency of the intelligent decision support system using open source dashboard technology in providing flexibility in the strategic planning processes and reducing mistakes in higher education? Under this main research question are three sub-research questions subsumed, listed down as follows:
1. How efficient is it to develop strategic planning processes in Higher Education?

2. How flexible is it to analyze strategic planning processes in Higher Education?

3. How faulty or correct is it to study strategic planning processes in Higher Education?

\section{TYPE OF ANALYSIS}

\subsection{Questioner}

\subsubsection{Demographic characteristics in Questioner}

The researcher believed that it was important to study the correlations between demographic and socioeconomic characteristics of the respondents. French (2014) confirms that demographics along with socioeconomic information about the sample respondents comprise an important array of telling indicators.

\subsubsection{Research Questions in Questioner}

Questionnaire questions are an important method of analysis and an inseparable part of obtaining any real results. The average results for the research questions are as shown below.

\begin{tabular}{|c|c|c|c|c|}
\hline strongly agree & agree & I do not know & disagree & $\begin{array}{l}\text { strongly } \\
\text { disagree }\end{array}$ \\
\hline $24.6 \%$ & $39.4 \%$ & $20 \%$ & $12.4 \%$ & $3.6 \%$ \\
\hline
\end{tabular}

\subsection{Interviews}

\subsubsection{Demographic Characteristics in}

Interviews

Where demographic characteristics are important characteristics and characteristics in the interview because of the knowledge of the path of development and targeting of the young group with a mix of practical experience from the real ground

\subsubsection{Research Questions in Interviews}

The research questions are the core of the subject and the medium of the goal because it is of great importance in obtaining the results of practical research from practice and work

\begin{tabular}{|c|c|c|c|c|}
\hline strongly agree & agree & I do not know & disagree & $\begin{array}{l}\text { strongly } \\
\text { disagree }\end{array}$ \\
\hline $34.9 \%$ & $40.8 \%$ & $3.7 \%$ & $15.7 \%$ & $4.9 \%$ \\
\hline
\end{tabular}

\section{LIMITATIONS AND RECOMMENDATIONS FOR FURTHER RESEARCH}

First, the study is a non-experimental study, i.e., conditions within the survey are not be modified to find out about any causation. Within this study, it is only possible to show connection and differences between variables. Due to limited time and cost conditions, the study is be based on convenience sampling of the target population. For this reason, any findings have to be treat carefully and cannot announced as representative. Despite all precautions, a possible defect of the instrument that was be used in the survey is that within a selfcompletion questionnaire survey participant can be concerned how their answers appear to the researchers. It is, therefore, possible that participants had answered dishonestly or in a socially desirable way. Another flaw could also be that in 
Saudi Arabia only 30 per cent of the participants were studying in the last year of A-levels. That means the majority of them were still in the penultimate year, which could cause bias in the answers, as they might not know definitely what they are going to do after school and only assuming their own decisions. The allocation between penultimate and final year was rather balance in Saudi Arabia. An additional limitation of the survey is that it only used students themselves and, therefore, data about the occupation and qualification of the parents can be distorted or simply wrong, as children might not know exact data about their parents ${ }^{\text {ee }}$ professions and qualifications. Owing to the limitations given earlier, it would be good to carry out a larger investigation with a representative sample size to confirm findings in general. It can also be useful to interview pupils from different types of Organizations such as private or state secondary schools in Saudi Arabia and general educating (Allgemeinbildendes Gymnasium) or economic (Wirtschaftsgymnasium) secondary schools in Saudi Arabia. Regarding the profession and the qualification of the parents, it might be constructive to involve parents in the survey and let them answer questions about their qualifications, apprenticeships, studies and occupations themselves. This would mean that the researchers would receive much more reliable data. For further research, it should also take into account that working with minors always needs particular care and protection. Within this study, the researchers had to go through a long and demanding procedure to receive permission to carry out the survey.

\section{CONCLUSION}

The study was concerned with the actual extent of introduced the DASH-IDSS, a novel interactive multi criteria Intelligent decision support system that based on Dashboard technology. The DASH-IDSS key features are intelligent tools to be using to assist decision-makers answer "what if", questions examine numerous alternatives very quickly and find the value of the inputs to achieve a desired level of output. It would be interesting for future research to investigate about what type of decision purposes dashboards are used for, assess the effects of using dashboard technology on decision making, how dashboards are used in organizations to deal with unstructured information sources. Even though the context of this study is limited to higher education, the results of this study could generalize to other areas.

\section{REFERENCES}

[1] Kothari, C.R., Quantitative Techniques, 2nd ed., New Delhi: Vikas Publishing House Pvt. Ltd., 2004.

[2] D J Power, Decision Support Systems: Concepts and Resources for Managers. Quorum/Greenwood, 2002.

[3] Few, S. Information Dashboard Design: The Effective Visual Communication Data, O־Reilly, pp.1-223. 2006.

[4] S Delisle, "Towards a Better Integration of Data Mining and Decision Support via Computational Intelligence," Proceedings of 16th International Workshop on Database and Expert Systems Applications, pp. 720-724, 2005.

[5] Arnott, D et al, A critical analysis of Decision Support Systems research, Journal of Information Technology,2005, 20(2), pp67-87.

[6] Shimizu T., de Carvalho M.M., Laurindo F.J.B, 'Theory and Case Studies' Strategic Alignment Process and Decision Support System', Idea Group Inc, 2006.

[7] Sauter, V. L. Decision Support Systems for Business Intelligence (2nd Edition), Wiley, Hooboken, USA, 2011, 1- 471.

[8] Julian, Ongonge. 'Master of Business', Relationship between strategic planning and organization's performance in nongovernmental organizations (NGOs): A case of actionaid, Kenya. University of Nairobi. Kenya, 2013.

[9] Wilker, J., \&Rusche, K. 'Economic valuation as a tool to support decision-making in strategic green infrastructure planning'. Local Environment, 19(6), 702-713, 2013.

[10] Hoadly, Ellen D; Jorgensen, Brian; Masters, Craig; Tuma, Nalli\&Wulff, Scott, 'Strategic facilities planning A focus on health care', Journal of Service Science, 3 (1), 15-22,2010

[11] Koutsoukis, Nikitas- Spiros; Ballesteros, Belen Dominguez; Lucas, Cormac A \&Mitra, Gautam. 'A prototype decision support system for strategic planning under uncertainty', International Journal of Physical Distribution \& Logistics Management, 30 (7/8), 640660,2000 .

[12] Fenton, Norman, and James Bieman. Software metrics: a rigorous and practical approach. CRC Press, 2014. pp. 28-36 